\title{
BEING TURKISH ERASMUS STUDENT IN SLOVENIA
}

\author{
Gözde Dağdelen
}

\author{
Research Assistant, Recep Tayyip Erdogan University, Turkey, gozdedagdelen@yahoo.com
}

\begin{abstract}
In this study, I focus on the experience of Turkish students who had been in Slovenia as an Erasmus student at 2014-2015 winter semester. I made depth interview 15 Turkish students. Erasmus that is providing cultural encountering opportunity has changed many things in the students mind. In this study, I try to figure out in what way the Erasmus experience made them change. According to this study, students start to consider their life conditions, daily routines, their customs and cultural habits significantly different viewpoint. I try to get insight about the experiences that makes possible these kinds of changes and how they interpret the cultural elements they got involved. I realized that how Erasmus experience is interpreted depends on gender. It shows diversification according to gender of the students. For female students, living abroad and being Erasmus student mostly means freedom and they realized how they have been living in restricted condition and they encounter different gender attitude than they used to. They enjoy walking at the street at night safely and feeling any social pressure about dressing style. For male students, Erasmus broadly means sexual freedom and kind of turning point in which they reconsider their future plans.
\end{abstract}

Keywords: Erasmus, Culture, Gender, Slovenia, Education

\section{INTRODUCTION}

I concluded this study during the winter season of 2014-2015 when I was an Erasmus student in Slovenia. I carried out an in-depth interview with a total of 15 persons out of which 7 were female and 8 were male who were studying at various faculties in Ljubljana University. Out of 13 of the respondents Erasmus was their first experience abroad. The ages of the respondents varied between 20 and 23.

\section{REASONS FOR JOINING ERASMUS}

Erasmus is viewed as the answer to the question 'what did you do to make life as a student fun. Sometimes the reply to this question may be 'I joined Erasmus to live my youth' or 'to have an adventure'. Other reasons for joining Erasmus can be considered to further English language skills, establish necessary networking for a future internship and the opportunity to travel in Europe.

I view Erasmus as an adventure. M/22/Business Administration

At a around the time when a person is in the second year of university one asks oneself is life passing me by. If the answer is yes then the result can be despondency which may have an impact in the future. My life at the university is empty, I just come and go. I chose to go to Europe to do something at least. That is why I chose Erasmus. S/22/Advertising

Students who come in the hope of developing themselves in a different education environment soon revise their targets when they are confronted with the challenges of the education. They focus on social life once they 
realize that the envisaged academic benefits are not going to happen.

Taking care of things is difficult but if that is the way it is so be it. I might just as well enjoy myself. Let's not turn sour. That is why I am fine now. I can relax now that I have put lessons on the back burner. M/21/Medicine

If the proficiency level of English of a person using Erasmus to develop language skills is below a certain level this development does not happen and inadequate English language skills will cause the student to withdraw and become isolated.

Our teachers encouraged us. They said you can improve your language skills. True I can express myself but those who are here have already mastered English as a second language. That is how it should be. I guess I fell victim to the wrath of my teacher. Go and learn. My English language skills are inadequate. I am asocial. I do not hang out socially very much. C/20/M. Eng.

Since the English language skills of students are determined with a proficiency level test of the relevant schools instead of an international or national central examination the English language proficiency levels of the students joining Erasmus may differ.

Those who attend lectures particularly in social sciences indicate that making presentations and participating in classroom debates has an impact on developing their language skills. It is possible to speak of the normalization of speaking English.

\begin{abstract}
Even if I claim that I did not speak very much at least I am beyond the phase where I stutter when I encounter a foreign language. I might not be able to carry on a fluent conversation but there is the issue of familiarity. Before I came here I had dealings with a few friends from Erasmus due to a project and if I had been to Erasmus before I would have been very different, I would have been more relaxed, more talkative. This would not have been because I developed my language skills profusely but because I would have been used to speaking and hearing a foreign language. M/21/Public Relations
\end{abstract}

\title{
3 REASONS FOR CHOOSING SLOVENIA
}

Slovenia has a lot of European countries as neighbors which facilitates traveling. Reasons for preferring Slovenia is because it is relatively economic in comparison with other European countries, the government distributes food coupons to students and the idea that there are less Turks there. A significant part of the participants had made the selection incidentally. In fact they claimed that they had been unaware of the existence of such a country before they got there. They had come as a result of the steering of their Erasmus coordinator in their relevant schools and by the incidental chance of Slovenia cropping up in the student placement.

\section{CULTURAL ENCOUNTERS AND SOCIAL LIFE}

One of the striking differences is the understanding of hygiene. Many situations which are considered unclean by Turkish students, does not appear to be a problem for the others. As an example going with bare feet into the common toilet and then going to bed like that is 'disgusting' for a Turkish student. Although the fact that the dormitory is co-educational is initially found perturbing it is quickly accepted. If fact being independent of the female identity and existing as a human being is positive in terms of normalizing life. However, the fact that the toilets are unisex generate two different attitudes. The initial and main attitude is 'disgust'. The second attitude is 'don't they have brothers? This situation is rationalized with what can be summarized as 'Do they use separate toilets in their homes?' It has been problematic for Turkish students where to dress after a shower. They have debated whether they should wrap a towel around themselves as they proceed through the corridor to their rooms or should they get dressed inside the shower booth and the Turkish students debated the issue among them and had a consensus on dressing in the shower booth.

When Turkish students compare themselves with foreign students they discover some differences. They mentioned Turkish students being more apprehensive about preparing presentations, losing passports, identity cards, etc. Turkish students have mentioned with astonishment and envious admiration that foreign students are calm even when they are faced with eviction from the dormitory which can be a major source of stress for a Turkish student.

The discovery of different gender roles also present itself as an enlightening experience. The excessive participation of women in the working life and executing jobs such as driving a buss which are considered 
men's jobs has enabled strong female identities to be more prominent. Different understandings in child rearing are also evident. Among such differences observed were waiting for a child who has stumbled to get up on his own without being lifted by a parent, having children spend a lot of time outdoors on school trips or as a part of education.

The students had noticed that people had smiles on their faces in the street, men and women were together and the lack of car horns and shouting. The students indicated that the food coupons they had been given made them feel appreciated.

The respondents mentioned that they were continuously confused with Arabs. The Turkish students felt uncomfortable when they were directed questions such as do you wear a 'Keffiyeh' (a headgear worn by Arab men), are all the girls dark, do you ride camels, is the headscarf mandatory in your country, do you know Arabic, do you use the Arabic alphabet' and they indicated that the image of Turks was not what it should be. Respondents who had established close relationships with Slovenians indicated that some of them used a word for Turks which had the same meaning as the word 'apache' in Turkish. Except for one respondent none of the respondents indicated that they had been treated poorly due to their Turkish identities in their daily lives. Two of the respondents indicated that the hosts of the Slovenian homes where they had been invited had displayed sensitivity regarding pork.

Another place where the respondents were uniquely astonished were the pedestrian crossings. The fact that vehicles stopped and allowed pedestrians to pass astonished them. In fact Turkish students who had dawdled at a pedestrian crossing without intending to cross did so because vehicles had stopped to let them pass and indicated that when they returned to their country they would be in mortal danger if they forgot the prevalent customs here. The astonishment in the adherence to a simple traffic rule says a lot about the social ambiance and threshold of civilization prevalent in Turkey.

I would be more relaxed if I lived here. What surprises me the most is that municipality busses stop when a pedestrian steps into the road. You are not on the pedestrian crossing, you are still on the pavement and you cross. This will be problematic in Turkey. We feel safe so we are not careful about roads any more. A few days ago I stepped into the road without looking, S. said that vehicles had stopped. M/21/Public Relations -Advertising

The first thing is shock, how do they stop. Ç/21/Economy

When I first came here what shocked me the most was that when I was crossing streets or just standing on the pavement and had not yet decided whether to cross or not the vehicles would stop. This shock effect lasted for a few weeks. I felt obliged to cross the street even if that was not my initial intention so as not to embarrass the drivers. Such sensitivity did astound us, I guess minds are slightly more advanced and self-control is better in Europe. S/22/ Advertising

\section{FRIENDSHIP WITH TURKS ABROAD}

All the students indicated that their families and inner circles had warned them about befriending Turks abroad. The reason for these warnings was to enable them to develop their English language skills. Furthermore, it is also possible to speak of respondents who did not prefer to be associated with Turkish students because they believed that the image of Turks in Europe was not positive and they did not want to share this image.

How can I explain, I did not want to lose my reputation. M/22/Business Administration

We tried to keep away from Turks as much as possible. The reason is that it would be productive. M/21/ Public Relations

Only one person mentioned a long term friendship established within the framework of Erasmus while the other students mentioned that the friendships in Erasmus had been established with the awareness of the impermanence of these affiliations.

It can also be alleged that the feeling of obligation has been added to the awareness of impermanence. The loneliness portrayed by the sentence "we are like fish out of water here" is accompanied with challenged friendships. It is safe to say that Turkish students abroad maintain their own agenda. The political, religious debates among the students in Turkey continue abroad and furthermore generate social pressure on each other through gossip. The friendship among the Turkish students during the first few months loses its intensity in time. The lifestyles of the foreign students and observing their agenda from such a close range and the liberal ambiance conflicts with the religious political contents of their debates and the efforts spent to have others accept what they consider to be right and the debates start to become less meaningful than usual which 
causes some students to distance themselves from Turkish student groups.

Although converging in a different context does not erase differences it gives students the opportunity to discover that there are things that they can share with people who they view as significantly different from themselves, people they thought they would not get along with.

\section{INITIAL REACTION TO A NEW CULTURE}

Students coming from the western provinces of Turkey view themselves as a part of European culture. Regardless of the word 'comfortable' with which they qualify European culture the initial reaction of students from the central and eastern provinces of Turkey on encountering European culture is the same; a feeling of being out of place. While the students from western provinces adapt to the new environment with more ease and enjoy themselves the other students indicate that they became introverted, they went through a process of self-preservation and became more tolerant of other cultures and life styles.

\section{SELF ESTEEM GAINING PROCESS}

For female students one of the most important gains of the Erasmus experience is self-confidence. The self confidence is gained by going abroad alone, living in a foreign country, administering a budget and even dealing with visa processing. This positive contribution of Erasmus to female students also manifests the truth of the learned helplessness women are raised in. The fact that enables the ability to travel alone to be perceived as a success or skill manifests the social reality of the restrictiveness they are raised in. If traveling from one European capital to another, making a visa application, managing a budget can be considered a personal milestone for a female university student this means that we have had much delayed start in the race.

Actually I gained some self-confidence. In conclusion I feel confident that I can overcome some things. I solved my problems. I never thought I could go abroad and deal with the visa procedures but I did it all on my own. P/20/E. Eng.

I gained self-confidence. I came here along. Initially I stayed at a hostel and roamed with a map in my hand. I found out what is where. I became more fluent. I spoke more confidently, I did not hesitate when I talked to people, I was not embarrassed. I overcame embarrassment. For example I went to Poland on my own. I went to a city that I knew nothing about. It was not like when I first came to Ljubljana, I had overcome that. The fear was gone. It was like I was going from Diyarbakır to Istanbul. I was calm. C/20/M. Eng.

Without being gender based I am a human being and have the right to do everything. I gained my power as a woman here in full. A/21/ A. Eng.

I gained a lot of self-confidence. For example the place we visit most frequently in Turkey is Istanbul. Here when you go to Germany you have to transfer in Belgium and you're like what am I doing. Then you get your act together. I am not afraid of going anywhere any more. I feel more self-confident regarding other people. People you meet do not perceive you differently because they have a mind and can think, they have different customs and traditions. It is a place where you are comfortable with everyone. In Turkey if you wear something different people will judge you strait away, here nobody cares about anyone. Everyone is respectful of one another. T/21/A.Eng.

\section{WOMEN'S EXPERIENCES OF FREEDOM}

The fact that female students could go out at night and feel safe made them aware of the unnamed curfew they had been imposed with. They felt what it was like to feel safe in the street, dress as they pleased, be just friends with a man and be viewed as a human being independent from gender.

It is very easy to go out, at home I used to be in by eight and latest at eight thirty. Here I have come to the dorm at 00.30 hours, it is very easygoing. B/21/E. Eng.

When I say easygoing I mean that you can go out at night and act freely without wondering if someone is going to approach you from behind. C/20/M. Eng.

\section{CONTRIBUTIONS OF ERASMUS}

It is indicated that although no major breakthroughs have been achieved in language skills at least the fear of 
speaking, a form of stuttering have been overcome. It is safe to say that the skills for living together with different cultures, tolerance for differences and the skills of getting along have increased.

Awareness that it is not easy to adjust to missing one's family enables the plans for living abroad to be more realistic.

Putting students in the position of managing their own budgets has increased their self-confidence and budget management skills.

Proving that they can handle any problems they encounter abroad is another achievement that can be attributed to Erasmus.

All of the respondents had visited more than one European country and they believed that their communication skills had increased and that they could communicate with people more easily which can be attributed as a contribution of Erasmus.

When asked how Erasmus had contributed to the male students almost all of them started talking with a meaningful smile. As the interviews progressed it became apparent that what they remembered as a contribution of Erasmus were the sexual experiences they had undergone. Male students manifested that the most significant contribution of Erasmus was the experience of sexual freedom, women approaching them without a judgmental attitude, without fearing them and providing them with a different educational platform to develop language skills.

Some of the female respondents can be assessed as persons 'who are confused after being freed from social pressure'. It has been alleged that the men in groups coming from Turkey separated from the groups and focused on romantic affairs.

\section{MEN'S EXPERIENCES OF FREEDOM}

Male students have indicated that observing that women are not afraid of them when they have contact, when they do not see tension and reticence in their faces has been a different and positive experience. The impact of freedom, the ease of being accepted as a human being before gender is valid for men as well as for women. The negative impact of patriarchy on women as well as men is manifested at this point. In addition male respondents indicated that it was also more comfortable talking to men. The comfort brought by the knowledge that everyone is transient allows a person the freedom of engaging with another without thought to their political views, who their parents are. The determination of prejudices is eliminated in a friendship affiliation which is established in a social environment where a culture of interpreting the class and political views of the encountered people does not dominate.

\section{COMPARISON OF EDUCATION}

There was a consensus on the education being more interactive than in Turkey. None of the students had oral examinations in addition to written examinations in their respective universities. They indicated that the obligation of making presentations in class enhanced their public speaking skills and underlined that they felt challenged because they did not have sufficient experience in their own universities.

The language of education is English which makes it difficult even for those students from universities which teach in English. The students are obliged to express themselves in English at all times and cannot speak Turkish when they fail to understand or are challenged.

All of the Erasmus students arrive with the expectations that the lessons will be easier. Therefore, the intensity of the courses, the fact that the exams are not held only at the end of the term but distributed over all the weeks in the form of homework and presentations force the students to study throughout the term at a certain pace. This form of study does not comply with the educational system in their country and is considered intense. After those who indicate that their reasons for joining Erasmus is to observe different educational environments and enhance their knowledge are faced with the challenge of the courses they concentrate on having a good time.

Another difference that is noteworthy is the fact that foreign students discuss the course subjects, projects in their daily lives outside lectures. The respondents found it interesting to encounter students who perceived the lecture subjects, the projects and homework presentations that they had prepared as a part of their lives.

They experienced a teacher student which is defined as "friendly". This is very different from the hierarchic attitude that they are familiar with. 


\section{CHANGES IN PLANS FOR THE FUTURE}

After the Erasmus experience the respondents understood that they needed to spend more effort on developing themselves. They indicated that they would act more enterprisingly regarding the assessment of internship opportunities abroad. The food coupons dispensed to students, fair income, witnessing people riding bicycles to work instead of driving, living in a regulated city without traffic problems makes living abroad an attractive option. Each respondent underlined their love for their country. It appears that Turkey is a loved country but one that is not preferred for living in. This is followed by leaving permanently and visited or becoming a mandated address which is returned to due to family, loved one or lack of alternative.

Reversely, the respondents are almost sure that they will experience a culture shock on their return. They mention the difficulty of re-adjusting to the unnamed nighttime curfew after the ambiance of freedom here, being consumed by the complex traffic in their own county after a social life progressing in an orderly fashion.

\section{HOW THEY VIEW THEIR COUNTRY FROM A FAR: “ACTUALLY WE DO NOT LIVE"}

Although only one respondent claimed to have stopped following the agenda in Turkey, the respondents indicated that the country's agenda was less painful from afar.

After experiencing life in Europe the respondents developed the perception that 'we are not ready for the European Union'. The reason for this is that the regional differences in Turkey are more paramount. While the cities in Slovenia share a similar socio-economic level on the whole, a comparison shows that the regional differences in Turkey are much more profound. When the respondents compared their country with the country they were visiting the respondents expressed their feelings with the sentence 'look at what they are dealing with and look at what we are leading with'. After the experience in Europe the crime rates in their country became more obtrusive. The fact that labor is appreciated, the shorter working hours, seeing the value given to human life makes their country appear more chaotic.

"Actually we are not living" U/22/M. Engineer

It is safe to say that the quote above summarizes the feeling lingering with the Erasmus students. Turkey is like an unwanted lover, the last option in plans for the future, a country where one remains because one cannot go elsewhere...

\section{REFERENCE LIST}

González, C., Mesanza, R., Mariel, P. (2011). "The Determinants of International Student Mobility Flows: An Empirical Study on the Erasmus Programme". Higher Education. Vol. 62, No. 4, pp. 413-430.

Maiworm, F., (2001). "Erasmus: Continuity and Change in the 1990s". European Journal of Education. Vol. 36, No. 4, Pp. 459-472.

Russell, J., Rosenthal D., Thomson, G. (2010). The International Student Experience: Three Styles of Adaptation". Higher Education. Vol. 60, No. 2, pp. 235-249.

Sherry, M., Thomas, P., Hong Chui, W. (2010). "International Students: A Vulnerable Student Population". Higher Education. Vol. 60, No. 1, pp. 33-46.

Teichler, U. (1996). "Student Mobility in the Framework of ERASMUS: Findings of an Evaluation Study". European Journal of Education. Vol. 31, No. 2, pp. 153-179.

Teichler, U. (2004). "Temporary Study Abroad: The Life of ERASMUS Students". European Journal of Education. Vol. 39, No. 4, pp. 395-408. 